To be published in Issues in mental health nursing, 2019, which should be cited to refer to this work.

DOI : $10.1080 / 01612840.2018 .1467984$

Music in seclusion rooms - development, implementation and initial testing of a music listening device

Angelika Güsewell, Emilie Bovet, Cédric Bornand, Alexia Stantzos and Gilles Bangerter University of Applied Sciences HES-SO

Author Note

Angelika Güsewell, University of Applied Sciences HES-SO, Lausanne College of Music, Switzerland; Alexia Stantzos, Lausanne University Hospital, Northern Psychiatric Department, Switzerland; Gilles Bangerter and Emilie Bovet, University of Applied Sciences HES-SO, School of Health Sciences Vaud, Switzerland; Cédric Bornand, University of Applied Sciences HES-SO, School of Management and Engineering Vaud, Switzerland.

Correspondence Address: Angelika Güsewell, Haute Ecole de Musique Lausanne, Recherche et développement, Rue de la Grotte 2, 1002 Lausanne, Switzerland. E-mail: angelika.gusewell@hemu-cl.ch 


\begin{abstract}
Although presented as a care measure, the use of seclusion rooms (SR) is controversial for both ethical and therapeutic reasons. Given that music seems to have a positive impact on psychiatric patients, offering them the possibility of listening to music in SRs might help to improve their care dimension. This study aimed to develop, implement and test a musical listening device that would be completely at patients' disposal, easy to use and beneficial to the quality of care provided in SRs. Over a twelve-week period, interviews were conducted with nurses $(\mathrm{N}=6)$ caring for patients placed in an equipped $\mathrm{SR}$. The music player was user friendly, encouraged patients to make choices and decisions, helping them to regain control over themselves and their behavior, and elicited various patient-nurse interactions, thus contributing to the establishment of a caring relation. Further research is warranted to examine whether the systematic use of the music player has an impact on the subjective experience of both patients and caregivers, and on daily ward routine.
\end{abstract}

Keywords: mental health nursing, seclusion and restraint, quality of care, music listening 
Music in seclusion rooms - development, implementation and initial testing of a music

\section{listening device}

\section{Introduction}

The use of seclusion and restraint in psychiatric care is a controversial practice that has attracted much debate since the beginning of modern psychiatry, as it entails the restriction of basic human rights such as autonomy, liberty and self-determination (United Nations, 1948). Psychiatric institutions have been criticized for their inhumane and arbitrary use of coercive measures and treatment in the past (Steinert \& Gebhardt, 2000), and coercive practices still “influence the image of psychiatry in the public eye” (Needham, Abderhalden, Dassen, Haug, \& Fischer, 2000, p. 254). Nonetheless, "there are times when physical restraint is the only possible course of action open to caregivers, and holding or tying a patient down is a better alternative than allowing patients to injure themselves or compromise others' safety” (Mohr, 2010, p. 3).

The challenge therefore is to strike the balance between two conflicting interests: ensuring the safety of patients and staff, on the one hand, and reducing the frequency of coercive practices in order to protect the patients' rights and dignity, on the other (Needham et al., 2000). In recent years, some countries have published standards regulating and improving seclusion (e.g., American Psychiatric Nurses Association, 2014; Haute Autorité de Santé, 2017). In Switzerland, the Swiss Academy of Medical Science (SAMS) published guidelines in 2015 with a view to raising awareness of coercive measures being major invasions of individual patient rights and of the requirement for ethical justification. The SAMS Guidelines

[...] take into account the provisions of the child and adult protection law which came into effect on 1 January 2013. These regulations not only specify essential procedural requirements with regard to coercive medical measures, broadly understood, but also - 
as part of the Swiss Civil Code (SCC) - help to harmonize at the national level the legal position which was previously characterized by substantial differences from one canton to another. (p. 5)

The SAMS Guidelines establish the need to (a) respect patient's autonomy and selfdetermination whenever possible, (b) use only those coercive measures that are both necessary and appropriate, (c) implement them only in an appropriate environment, (d) communicate with the patient concerned - of crucial importance - before, during and after a coercive measure, and (e) document all such measures (Swiss Academy of Medical Science, 2015, pp. 13-15).

Beyond the ethical issues, there is little evidence or certainty regarding the therapeutic effect of using seclusion rooms (SR). A systematic review of the literature published between 1985 and 2006 concluded that insufficient empirical evidence was available to consider seclusion as a safe and effective intervention in acute psychiatric inpatient settings (Nelstrop, Chandler-Oatts, \& Bingley, 2006). Seclusion aims to reorganize the patient-nurse interaction in a sustained, containing and soothing manner (Vignat, 2009), to reduce space and to ritualize time, thereby enabling the patient to regain control of his or her psychic state and behavior and contribute to establishing (or restoring) a therapeutic alliance. However, most patients do not perceive the therapeutic function of seclusion (Bardet Blochet, 2009; Friard, 2009). Feelings of isolation and abandonment dominate, often accompanied by anger or anxiety (Bonner, Lowe, Rawcliffe, \& Wellman, 2002; Holmes, Kennedy, \& Perron, 2004; Martinez, Grimm, \& Adamson, 1999; Meehan, Bergen, \& Fjeldsoe, 2004; Wynn, 2004). Additionally, the reduction of sensory stimulation (i.e., hypostimulation) can present certain risks: “[when] deprived of the perception of external elements, the perception of one’s own body increases. This is worrying, as, generally speaking, we live in a silent body” (Bayard, 2011, p. 79). Since sensory deprivation, even of relatively short duration, can cause psychotic 
symptoms (Mason \& Brady, 2009), it is recommended to intersperse the period of isolation with “moments of normal stimulation” (Bovet, 2009, p. 25).

It is therefore understandable for SR use to lead to the contradictions and paradoxes that caregivers tend to experience as unsatisfactory and stressful (Korkeila, Koivisto, Paavilainen, \& Kylmä, 2016). Firstly, seclusion should foster a mode of close interaction with patients, in theory; in practice, however, it tends to undermine trust and weaken the desired therapeutic alliance (Bardet Blochet, 2009; Friard, 1998). Secondly, given that nurses learn the importance of ethical practice during their professional training, and that "taking into account the interests of patients and aiming to provide the best possible care is central element of their system of values and professional identity” (Jaafarpour \& Khani, 2012, p. 1761), ethical dilemmas relating to the restriction of a patients' autonomy become a major stressor for them and negatively impact their job satisfaction (Ellefsen, 2002).

In the light of these concerns, healthcare teams are seeking interventions to improve the care dimension of SR use. One promising approach is to offer patients the possibility to listen to music. It aims to reduce hypostimulation and feelings of loneliness and abandonment and is supported by empirical studies that indicate that listening to music induces relaxation, decreases pain and blood pressure, and slows heart and respiration rates (review by Lin et al., 2011). At the neurological level, it seems to alter electrical brain activity during acute psychotic episodes: in an experimental study with 15 subjects recruited from an acute inpatient psychiatric unit, listening to music led to a statistically significant decrease of dysfunctional brain activity during acute psychotic episodes (Morgan et al., 2010). At the psychological level, musical listening proved to have a positive impact on depressive symptoms. In a study by Hsu and Lai (2004), an experimental group ( $\mathrm{N}=27$ ) listened to soft sedative music as therapy for 30 minutes every day over a period of two weeks and then 
scored significantly higher on Zung's self-administered depression scale (SDS; Zung, 1965) than the control group $(\mathrm{N}=27)$.

There is already a small number of music listening interventions and devices developed specifically for psychiatric care. The "Individualized Music Intervention for Agitation" (IMIA; Gerdner, 1992) is a tool designed for patients with dementia. It comprises a musical preference assessment questionnaire, used to create individualized playlists for patients, and two observation grids to identify early warning signs indicating a crisis. Using these tools, a 'care plan for use of individual music' can be designed for each patient. The IMIA relies on the assumption that a familiar musical excerpt can stimulate the long-term memory of patients with dementia and thus mitigate or prevent crises by diverting their attention (Gerdner, 2012).

Designed for patients with dementia as well, the "Picture Gramophone” Multimedia Program (PG; Topo, Mäki, Saarikalle, Clarke, Begley, Cahill, \& et al., 2004) can be customized to include favorite songs, as well as photos. In addition to inducing well-being through music and stimulated memories, it promotes and reinforces autonomy and feelings of competence in patients by allowing them to select the music and photo slideshows via a touch screen device. According to the staff of five day-care dementia units in Finland, Ireland, Norway and the UK, use of PG had a 'positive' or 'very positive' impact on patients' mood (17 out of 23) and social interaction (16 out of 23).

Finally, there is the Danish "Music Star" (Lund, Bertelsen, \& Bonde, 2016) consisting of various playlists and a sound system and implemented as a permanent installation in patient rooms in psychiatric intensive care units. Here again, the aim is to empower patients to "choose music suited to their needs and preferences, counteracting the general tendency to pacify patients in the hospital milieu” (p. 52). Music Star has been used in four research projects, all launched in 2016. Solid results based on analyses of quantitative as well as qualitative data cannot, therefore, be reported yet. However, on the basis of observations, 
personal reports and anecdotal data, it appears that the device is used "continuously and intentionally by staff and patients in the wards" (p. 62), and that overall, the "response is positive from both patients and the staff” (p. 63).

Introducing new technology into professional practice is never without difficulty nor a matter of course (e.g., Bobillier-Chaumon \& Dubois, 2009). Firstly, acceptance is a function of a number of contextual factors, e.g., the structure and culture of a company (Lapointe \& Rivard, 2005), the specificities of the professional sector (Sobol, Alverson, \& Lei, 1999), the presence of a framework for the support and involvement of the different actors, users' levels of digital literacy and familiarity with the technology (Larose, Grenon, \& Palm, 2004), their perceptions and their age (Larose, Grenon, \& Lafrance, 2002). Secondly, acceptance is contingent on the characteristics of the technological device itself in terms of functional ergonomics, i.e., its usability (Tricot et al., 2003). Thirdly, it depends on the perceived usefulness of the objectives set for the implementation of the new technology. In the field of health care, user acceptance is known to be markedly higher where technology contributes to improved quality of care, is relevant to the patients, and directly benefits them (e.g., Curaviva, 2014; De Veer, Fleuren, Bekkema, \& Francke, 2011).

There is empirical evidence of the positive impact that listening to music has on psychiatric patients (Hsu \& Lai, 2004; Lin et al., 2010; Morgan et al, 2010). The use of radio and music players is widespread in psychiatric institutions, and in some cases, rooms are even equipped with an audio system to play music. Several music listening interventions or devices have already been developed specifically for the context of psychiatric care (Gerdner, 1992; Lund et al., 2016; Topo et al., 2004). All of them propose a thought-out selection of music pieces to the listeners, and give them the possibility to choose music suited to their needs and preferences, thus supporting their autonomy. However, none of these interventions or devices has been implemented and tested in SRs up to now. In the light of this, the overall objective of 
this study was the development, implementation and initial testing of a musical listening device that would meet the specific requirements of SRs and be completely at patients' disposal. More specifically, the aim was to assess its perceived usability (i.e., ease of use), perceived usefulness (i.e., contribution to the quality of care), and acceptance (i.e., behavioral intention to use), as these parameters are known to determine the actual use of new technologies (Venkatesch \& Davis, 2000).

\section{Method}

Development of the music listening device

Technical aspects. The main challenge in developing the music listening device was overcoming safety concerns. Seclusion rooms must meet strict safety standards. In Switzerland, breakable and therefore potentially dangerous objects are prohibited. This excluded providing patients with portable music listening devices, such as tablets and/or wired headsets. Under these conditions, the optimal solution was the development of an audio device $^{1}$ controlled by the patient through a tactile interface integrated into the wall of the SR and connected to loudspeakers hidden behind ventilation grids (see Figure 1a). Outside of the SR, tablet computers containing the music files and control software were housed in a separate cabinet (see Figure 1b). The patient-facing interface consisted of a plastic panel with engraved control buttons (for the standard functions of media players, i.e., play/pause, stop, skip forward, skip backwards, volume up and volume down) and four buttons to select pieces of music by category (see Figure 1c).

Insert Figure 1 about here

Music selection. Departing from the method used with the PG (Topo et al., 2004), which allows patients with dementia to select and listen to music familiar to them and thus to

\footnotetext{
${ }^{1}$ For a detailed description of this audio device, see $\mathrm{xxxx}$
} 
connect with their personal history, the idea in this research project was to provide the patients with a selection of unfamiliar pieces of music. This choice of approach was based on the assumption that unknown music would foster an open and attentive listening of the music available, and thus connect the patients with their immediate feelings and emotional needs, instead of their biographies and memories. Furthermore, this procedure meant all patients would be presented with an identical selection of music, adding merit to the research angle of the project by increasing data comparability. Finally, a practical reason also supported standardizing the music selection: the placement of patients in SRs is generally a response to an emergency situation, removing the luxury of being able to ask them or their relatives for playlists.

To avoid confusion and overload, it was decided (after consultation with the care team) to provide a limited choice of 20 pieces of instrumental music, each lasting 5-10 minutes, covering a variety of genres, and not being too well-known (i.e., no chart-topping music). The method for gathering the initial pool of pieces meeting these criteria was as follows: each member of the research team made suggestions, mainly from the classical repertoire, film music, jazz, and popular or folk music (pop, rock, soul, and R\&B pieces tend to be vocal and better known). Then, the research team (5 persons) debated the inclusion of each piece into one of the nine dimensions of the Geneva Emotional Music Scale (GEMS; Zentner, Grandjean, \& Scherer, 2008), i.e., joyful activation, wonder, power, nostalgia, sadness, tenderness, transcendence, peacefulness, and tension. This led to a shortlist of 50 pieces (4-5 per dimension) whose allocation was agreed unanimously. Lastly, a group of 40 volunteer listeners (20 women, 20 men; aged 14 to 75; $M=37.5$ ) from various professions (i.e., music students, future and current teachers, engineers, retirees, secretaries, a gardener, commercial assistants, a historian, a university lecturer, a dean, doctors and nurses, an actor) were asked to 
indicate in an evaluation grid the two dimensions of the nine GEMS dimensions (see above; Zentner et al., 2008) each of the pieces evoked most to them.

In our analysis, transcendence was hardly ever chosen, either because the term did not mean very much to the listeners, or because in their perception the pieces did not convey this particular emotional content. The remaining eight dimensions tended to appear in groups of two or three. This resulted in four categories of emotional content, namely: joyful activation (i.e., joyful activation flavored with wonder), nostalgia (i.e., nostalgia flavored with sadness and calm), tension (i.e., tension flavored with power and sadness), and calm (i.e., calm flavored with wonder and tenderness).

A final selection of 20 pieces which had been assigned almost unanimously to one of the four categories of emotional content was compiled (see Appendix 2) and uploaded to the tablet computers. This music selection was accompanied by short, easy-to-read fact sheets on the composers, performers and songs available to both caregivers and patients in the form of laminated paper.

\section{Initial testing of the device}

Data collection. Data collection took place in spring 2014 in the psychiatric hospital of xxx. Over a period of twelve weeks, whenever a patient was secluded, daily telephone interviews were conducted with six nurses (5 women, 1 men) aged 35 to 55 assigned to nine patients who had successively spent several consecutive hours or days in a SR equipped with the newly developed music listening device. The aim of these short (10-15 minutes), semistructured interviews with one of the researchers was to collect information on the previous 24 hours regarding the use of the music player. The same questions were asked every day. They related to (a) the patient currently placed in the SR - e.g., age, gender, diagnosis, condition; (b) the explanations given on the operation of the device - i.e., the patient's reactions or questions, specific arrangements for use; (c) the patient's music listening 
strategies - e.g., duration and frequency, moment in time, preferred pieces; (d) interactions and discussions occurring around music - e.g., elicitor, content, etc.; and (e) caregivers' subjective experiences .

Ethical conduct. Approval for this study was obtained from the Ethics Boards of the Department of Psychiatry, xxx. The study protocol was in accordance with the ethical standards of cantonal and national research committees, as well as with the standards of the Declaration of Helsinki and its later amendments. Participation was voluntary for caregivers (all agreed to be interviewed). Service users-received information on the study upon dismissal and signed a consent form if they agreed to the use of the data collected during their stay in the SR. Five patients ( 4 women, 1 man) aged 26 to 42 gave informed consent. Patient's safety and well-being was a primary consideration of the study: nurses were instructed to immediately switch off the music listening device should a patient ask for it, or should his or her symptoms seem to be exacerbated by the music.

Data analysis. All interviews were audio-recorded and transcribed in full. A content analysis using HyperResearch ${ }^{2}$ and taking an integrated approach was then performed by two of the researchers: initial (i.e., a priori) codes were derived from the research questions discussed above, namely (a) usability of the device, (b) impact on quality of care, and (c) acceptance of the device on the side of the care team, and then further refined according to ideas and concepts identified during the process of data analysis (i.e., emergent codes).

\section{Results}

\section{Usability of the device}

Overall, the device worked well during the test period. One single technical problem was reported: a patient [P1] could not stop the music, and the nurse on duty [N1] had to switch off the system and restart it again. Otherwise, in the stripped-down room, the interface with its

\footnotetext{
${ }^{2}$ HyperResearch is a software for qualitative data analysis http://www.researchware.com/products/hyperresearch.html
} 
symbols seemed to provide a visual and tactile stimulation point that could neither be overlooked, nor ignored. All patients tried it out at one time or another during their stay in the SR, and quickly became familiar with its use, either by trial-and-error, or by systematic exploration. One patient said at the time of discharge that he felt the device had been designed “with patients in mind” [P3].

According to the caregivers, the limited choice of music seemed sufficiently large and varied for the short period of time patients spent in SRs. Furthermore, it helped them to distinguish clearly between categories and allowed them to easily find the pieces they wished to (re)listen to. The concern that the music selection might not be close enough to the musical universe or the listening habits of the patients, and thus discourage them from listening, proved to be unfounded. For example, after listening to the beginning of the first piece upon admission, a patient said "pff, classical...” [P2] and then asked for her iPod. The nurse [N4] explained that she was not allowed to use her personal music player in the SR. Following this discussion, the patient ignored the fully installed musical listening device for the rest of the day. However, the next day, she started listening to music, mainly from category 4 (calm). Another patient was asked if he would have appreciated other music. He answered that he found the music "interesting” and that anybody could notice what unfamiliar music releases within them [P3].

Overall, the music, and in particular the tension category, did not exacerbate the condition of agitated or confused patients. However, there was one report of a situation in which the music triggered uneasy feelings: a patient [P3] who favored the calm category asked the nurse [N4] to turn up the volume higher and higher, up to the maximum. After a quarter of an hour of listening at the maximum level, he stopped the music all of a sudden because he felt he ought to join in and play the guitar, an idea that stressed him. 
Those who used the fact sheets found them very useful. According to one of the caregivers, “they open the way for exchanges. It’s quite an important tool to work with” [N3]. One patient [P2] asked for them regularly, as they helped her to select the music. Another [P3] said that they helped him to feel connected with the music. However, the sheets tended to disappear, so one patient [P3] finally suggested to post them on the door of the SR. Furthermore, one nurse [N1] expressed concern that the laminated cards might cause injury (which did not occur).

\section{Impact on the quality of care}

Overall, the caregivers felt the implementation of the device improved the quality of care provided in the unit. Different reasons were given for this. Firstly, the device encouraged patients to make choices and decisions. The caregivers' narratives show that each patient made use of the device in his or her own way: choosing between musical listening and silence; adjusting the volume; listening to certain pieces many times over or, to the contrary, allowing all the pieces in a category to play; lying on the bed, sitting, or standing; remaining motionless or dancing or singing. "In a seclusion room, where everything is closed off and where patients have no control, the music grants them the responsibility to decide. It's really something we felt very strongly” [N3].

Secondly, the device helped patients to regain control over themselves and their behavior. One patient [P2] used the device too "energetically," impatiently punching the buttons or hitting them with her fists. As the musical device was not designed for such impetuous use, it soon stopped functioning correctly. When the patient alerted the caregivers, they restarted the software. This cycle repeated two or three times before the patient realized that for the music to play she must use the buttons more precisely and calmly. From within her state of confusion, she learned to redirect her attention to the environment and to contain her agitation. No restrictions were introduced regarding the time, duration or volume of listening. 
Despite this great freedom given to patients, none abused it, and, according to the caregivers, no attempts were made to damage the device (whereas the walls and doors of the SR were targets for violence). When asked why, patients explained that there was no sense in damaging the only object in the room that "belonged" to them (i.e., because they had control over the device, they considered it as their own).

Thirdly, from the caregivers' point of view, music listening was far more than a form of entertainment proposed to patients to interrupt the silence or to pass the time: it created opportunities to enter into a dialogue, to talk about something other than disease and symptoms. The following examples illustrate the variety of discussions that arose around music and music listening. One patient [P3] told a caregiver [N4] that he had repeatedly listened to a piece of music with which he was unfamiliar but which he particularly liked. He explained that the piece moved him deeply, perhaps because he was in withdrawal [he was a drug addict], but also because the music gave him access to his inner world. The nurse proposed listening to the piece together. Then they read the descriptive sheet. It turned out that the piece was by Edvard Grieg, a Norwegian composer. Given his origins, the patient associated with this piece - his father was from Norway - which led him to talk about the special relationship he maintained with his father. The next day, the same patient [P3] asked the nurse [N2] to select music for him. He wanted music to calm him down, since he felt very tense, and needed advice, as this was a type of music he did not know at all. Another patient [P2] explained to the nurse [N4] that she liked the sound of the Oud $^{3}$ (i.e., in "Astrakhan café”), as it reminded her of her Romanian culture and origins. A bit later, the same patient laughed out loud while listening to the music of category 3 (tension), and told the nurse that she found it "quite weird" to be locked up, while at the same time offered "such music." A

\footnotetext{
${ }^{3}$ Oud $=$ short-neck lute-type, pear-shaped stringed instrument with 11 or 13 strings grouped in 5 or 6 courses, commonly used in Persian, Greek, Turkish, Jewish, Byzantine, Azerbaijani, Arabian, Armenian, North African, Somali and Middle Eastern music. https://en.wikipedia.org/wiki/Oud
} 
few hours later on the same day, she had a discussion with the nurse about the Liszt “Consolation” (category 4, calm) and how music opens up emotions (i.e., catharsis ${ }^{4}$ ). Finally, a patient [P5] who was about to be discharged refused to leave the SR because then she would not have access to the music any longer. Music, she explained, allowed her to travel, to take inner voyages. However, when the nurse [N6] tried to ask her to detail these voyages, she refused to answer.

Acceptance of the device

Caregivers reported how their perception of the system evolved over time. Doubt and skepticism gave way to a more convinced attitude: "I confess that the first time you presented the project, I was really skeptical and I looked at my colleagues with wide eyes, saying to myself these people do not know what a psychotic patient in crisis is! I thought about the patients interacting with the device and was sure it wouldn't work. I'm generally open to change and progress, but there I was really wondering what we were getting ourselves into. I’ve since completely changed my perception” [N4].

Perceptions mainly changed as a consequence of (positive) experiences. One nurse [N1] reported that she did not dare to propose the device upon admission to a patient [P2] subject to pronounced logorrhea, thinking that it would “agitate her further.” Having spoken by phone to one of the researchers at the end of the day, she decided to return to the patient and explain to her how to use the interface. She was surprised to note the patient following her explanations attentively, and even more surprised, later in the evening, to see her playing music to help her sleep. Being able to propose something specific to reduce the symptomatic agitation of the patient was a positive experience which encouraged the nurse to persevere.

\footnotetext{
${ }^{4}$ Catharsis = the purging of the emotions or relieving of emotional tensions, especially through certain kinds of art, such as tragedy or music. http://www.dictionary.com/browse/catharsis
} 
After a few weeks of use, it emerged that the pieces provoked interesting reactions not only among patients but also caregivers (many listened to them in their car, going to/from work, to familiarize themselves with them and to be able to discuss them with patients). While most of them would never previously have even thought of listening to a Liszt solo piano piece or a Schumann string quartet, having now been somehow obliged due to the implementation of the device, they were surprised to discover that repeatedly listening to this unknown repertoire had enabled them to become familiar with it, and even to appreciate it. One caregiver [N3] discovered that Debussy ('tension' category) was “soothing and calming at difficult moments." Since then, he listened to the pieces in a targeted way to regulate his own affective states.

Several difficulties related to the new procedures and routines that had to be established around the music listening device were mentioned. Despite the good experience gained with the music player, its integration into the daily practice of the ward seemed far from acquired after the three-month test period: sometimes, caregivers forgot to switch on the device when a new patient was placed in the SR; patients who were highly agitated or confused upon admission did not always receive explanations about how the player worked at the outset; patients were not systematically provided with the fact sheets about the composers, performers and songs, usually because they could not be found when needed.

\section{Discussion}

The aim of this study was the development and initial testing of a music listening device that would firstly be easy to use for both patients and caregivers, secondly contribute to the quality of care in SRs, and thirdly be well-accepted by the nurses. Once developed, the prototype was installed in one of the SRs of the acute psychiatric ward of the xxx hospital in xxx. Qualitative data on its use and on both patients' and caregivers' experiences and perspectives were collected by calling the nurses in charge on a daily basis whenever a patient 
was placed into the SR over a period of twelve weeks. Several themes emerged from the content analysis of this data.

Technically speaking, the device proved to work well. The main issue raised with respect to usability concerned the appropriateness of the music selection. In contrast to the caregivers' initial doubts regarding the style or the number of the pieces proposed, the experience gained during the test period indicated that neither of these aspects was actually problematic, quite to the contrary: the limited number of relatively short pieces as well as the categorization according to the emotional content facilitated navigation. With regard to style, all patients found music suited to their needs and preferences, even if some of them showed little enthusiasm upon initial hearing. Finally, the fact that the music was completely unknown to the patients encouraged them to deal with their needs and emotions of the moment, and elicited various associations.

With respect to usefulness, three main topics emerged from the interviews with the caregivers. The first was in line with expectations and previous interventions (Gerdner, 1992; Lund et al., 2016; Topo et al., 2004) in that the device allowed patients to make choices and decisions, thereby increasing their feeling of autonomy and self-determination. The second topic was that the device appeared to help some patients regain control over themselves and their behavior. This unanticipated outcome points to the importance of the 'object', not only the 'music,' and calls for a clearer distinction between the two in future studies. Finally, the third topic concerned the various in-depth exchanges that took place between caregivers and patients around music and music-listening. Listening to music seems to create a new relationship space - between inner and outer realities, between the inside and the outside, an “intermediate” or "transitional” space (Winnicott, 1975) - where patients and caregivers can meet. This is an interesting outcome, as interactions between patients and caregivers tend to be minimized in the particular setting of the SR (Hoekstra, Lendemeijer, \& Jansen, 2004): the 
“care” patients receive is often limited to the monitoring of their medication and their physical health. There is not enough time for what nurses and literature (e.g., Barker \& BuchananBarker, 2005; Cameron, Kapur, \& Campbell, 2005; Moyle, 2003; Stevenson, Barker, \& Fletcher, 2002) consider to be the very essence of acute psychiatric care, namely the establishment of a caring relationship, i.e., an interaction based on personal contact and communication between the two parties, in which the patient is at the heart of the concerns (Rask \& Brunt, 2007).

With respect to acceptance, our data show that overall, it increased over the twelve weeks of the test period. This is in line with the Technology Acceptance Model (TAM2; Venkatesch, \& Davis, 2000), according to which acceptance is contingent on positively rated usability and usefulness. However, we could also see that this overall acceptance of the new music listening device did not lead to the full integration of the new procedures and routines related to it, a difficulty also mentioned by Lund et al. (2016).

\section{Implications}

The starting point for this research was the discomfort, and in some cases dissatisfaction, of a nursing team with the quality of care provided to secluded patients in its acute psychiatric ward. The literature indicates that the autonomy of patients in psychiatric-care settings, albeit relative, is an important factor in caregivers' job satisfaction and well-being at work. According to Jaafarpour and Khani, “[d]uring their education, nurses learn the importance of the ethical practice” (2012, p. 1761). A central element of their system of values and professional identity is taking into account the interests of patients and aiming to provide the best possible care. It follows that ethical dilemmas, often relating to the restriction of a patient's autonomy in acute psychiatry, are a major stressor for healthcare teams and negatively impact job satisfaction (Ellefsen, 2002). The same applies to the demand for 'effective' treatments - i.e., those tending toward a medical approach to the day-to-day work 
of caregivers in psychiatry - which oppose the humanistic and existentialist philosophy of care, and thus once more constitute a source of conflict (Hummelvoll \& Severinsson, 2001). Indeed, in the daily reality of SR use, the 'care' given to patients is often limited to monitoring medication and/or physical health, and there is insufficient time for what both caregivers and the literature (e.g., Stevenson, Barker \& Fletcher, 2002; Moyle, 2003; Barker \& Buchanan-Barker 2005; Cameron, Kapur, \& Campbell 2005) consider to be the essence of acute psychiatric care: the establishment of a caring relationship, i.e., an interaction based on contact and communication between the two parties in which the patient is at the centre of concern (Rask \& Brunt, 2007).

Studies containing detailed analysis of dialogue and interaction between nurses and patients are not numerous. Cleary, Hunt, Horsfall and Deacon (2012) systematically reviewed the corresponding literature, mentioning 18 publications that touch upon the sophisticated communication that develops in a caring relation. However, it appears none of these studies considers the conditions or facilitators that enable the development of such communication. Furthermore, none are based on a theoretical model. One that may prove helpful in this respect is Rask and Brunt (2007). Starting from a phenomenological understanding of the caring relationship, the authors propose modeling the various types of interaction that may take place between caregivers and patients. By examining if and how the systematic offer of the music player to patients impacts patient-nurse interactions, further research could thus contribute to a better understanding of the link between the nature and quality of care provided in acute psychiatric wards and the well-being at work of care teams.

Merely deploying a new technological tool is insufficient to change practices; real integration involves a reconfiguration of workplace organization, skills and roles (BobillierChaumon \& Dubois, 2009). Although developed for the educational context, the systemic model of Depover and Strebelle (1979) is easily transferrable to the field of care. It 
distinguishes three stages of integration of innovations, and, when applied to the results of the present study, it reveals that, at the time of the data collection, the care team can be described as having surpassed the initial phase of adoption, which is characterized by "the decision to change something in practice led by personal belief or external pressure” (p. 80), and entered the implantation phase where "the decision to change adopted during the adoption phase manifests itself as a desire to engage in a process leading to a modification of practices [...]. This phase translates into perceptible changes not only in practices but also in the environment in which these practices take place” (p. 81). However, the subsequent habituation phase, which is characterized by "the recourse to new practices being a regular and integral part of normal activities not requiring external support” (p. 82), is still a long way off. In order to reach this phase, long-term support - in the form of technological assistance, continuing education, a greater, general emphasis on music and music listening at the hospital, research activities aimed at documenting the use and impact of the system and, above all, joint reflection - will be required to develop and implement a systematic modality of care structured around music.

\section{Limitations}

One limitation of this study is that data were collected over a relatively short test-period in a single acute psychiatric ward and therefore concerned only a very limited number of 'cases' (i.e., patients spending several hours or days in SRs). A long-term multi-site study would overcome this first limitation and enable a more reliable conclusion based on a larger data set. Another limitation is that only nurses were interviewed. The point of view of the patients was thus captured only indirectly. A future study should include questionnaires or interviews conducted with patients upon discharge. A third limitation is the fact that only qualitative data were collected. Objective information about the actual listening habits of the patients is thus missing. As the control system of the musical listening device now allows for the exportation 
of its data log, quantitative analyses will be possible in the future in order to better understand the way it is used by different patients. Additionally, standardized measurement instruments could be used to capture the subjective experience of both patients and nurses. This would enable the identification of significant changes in nurses' well-being at work between the implementation of the device and after several months of its use. This would also allow the scores of an experimental group (i.e., patients placed in a SR equipped with the music listening device) to be compared with the scores of a control group (i.e., patients placed in a SR without music listening device). Finally, as all patients placed in the SR during the test period did not give informed consent, those who participated might well differ from those who did not, meaning that sampling biases may be present. This is difficult overcome, however, as patients' free choice and welfare are overriding considerations in any clinical study.

\section{Conclusion}

As part of an exploration of the potential of a newly developed musical listening device to contribute to the quality of care in seclusion rooms, the research interviews conducted with nurses during a twelve-week test period showed the device seemed to contribute to the autonomy and perceived self-efficacy of patients and to stimulate new forms of exchange and interaction between caregivers and service users. However, these findings need to be verified in a broader sample of patients and caregivers. In addition, qualitative data should be crossreferenced with quantitative data, both on the actual use of the device by patients and on the subjective experience of the parties involved. With this kind of broader data, it will be possible to derive more solid conclusions on the actual impact of the music device in the context of acute psychiatric care.

\section{Acknowledgments}


This research project was only made possible thanks to financial support of xxx. The authors would also like to express their thanks for the positive support received to the administrative, technical, and medical staff of xxx Hospital, particularly xxx. And finally, they wish to thank $\mathrm{xxx}, \mathrm{xxx}$, and $\mathrm{xxx}$ who took part in the early stages of the project.

\section{Conflicts of interest}

The authors report no conflicts of interest.

\section{References}

Académie Suisse des Sciences Médicales (2017). Directives médico-éthiques. Mesures de contrainte en médecine. Berne (Switzerland) : Académie Suisse des Sciences Médicales.

American Psychiatric Nurses Association (April 2014). Seclusion \& Restraint Standards of Practice. Retrieved from: www.apna.org/i4a/pages/index.cfm?pageid=3730.

Bardet Blochet, A. (2009). Les chambres fermées en psychiatrie: poursuivre le débat pour dépasser les conflits. Schweizer Archiv für Neurologie und Psychiatrie, 160(1), 4-11.

Barker, P. \& Buchanan-Barker, P. (2005). The tidal model: A guide for mental health professionals. New York: Brunner-Routledge.

Bayard, J.-M. (2011). Hypostimulation: Un programme de soins intensifs controversé. Diagonales, 79, 4-9.

Bobillier-Chaumon, N., \& Dubois, M. (2009). L'adoption des technologies en situation professionnelle: Quelles articulations possibles entre acceptabilité et acceptation ? Le travail humain, 72, 355-382.

Bonner, G., Lowe, T., Rawcliffe, D., \& Wellman, N. (2002). Trauma for all: A pilot study of the subjective experience of physical restraint for mental health inpatients and staff in the UK. Journal of Psychiatric and Mental Health Nursing, 9(4), 465-473. doi:10.1046/j.13652850.2002.00504.x 
Bovet, P. (2009). Mesures de contention dans les hôpitaux psychiatriques du Canton de Vaud. Rapport adressé à M. le secrétaire du DSAS, à la demande de M. le Conseiller d’Etat P.-Y. Maillard. Lausanne: CHUV.

Cameron, D., Kapur, R., \& Campbell, B. (2005). Releasing the therapeutic potential of the psychiatric nurse: A human relations perspective of the nurse-patient relationship. Journal of Psychiatric and Mental Health Nursing, 12, 64-75.

Cleary, M., Hunt, G. E., Horsfall, J., \& Deacon, M. (2012). Nurse-patient interaction in acute adult inpatient mental health units: A review and synthesis of qualitative studies. Issues in Mental Health Nursing, 33(2), 66-79. doi:10.3109/01612840.2011

Curaviva (2014). Décharger les soignants et non les remplacer. Retrieved from: https://www.curaviva.ch/Infos-specialisees/Dossiers-thematiques/Technologiedassistance/oRenv2rN/PQBbv/?lang=fr

Depover, C., \& Strebelle, A. (1997). Un modèle et une stratégie d’intervention en matière d’intégration des TIC dans le processus éducatif. In L. - O. Pochon \& A. Blanchet (Eds.), L’ordinateur à l'école : de l'introduction à l'intégration (pp. 73-98). Neuchâtel, Suisse : Institut de recherche et de documentation pédagogique (IRDP).

De Veer, A. J., Fleuren, M. A., Bekkema, N., \& Francke, A. L. (2011). Successful implementation of new technologies in nursing care: A questionnaire survey of nurseusers. BMC Medical Informatics and Decision Making, 11, 67. doi:10.1186/1472-6947-1167

Ellefsen, B. (2002). The experience of collaboration: a comparison of health visiting in Scotland and Norway. International Nursing Review, 49, 144-153. doi:10.1046/j.14667657.2002.00117.x

Friard, D. (2009). Isolement: Trouvez une autre solution! Santé Mentale, 139, 24-29. 
Gerdner, L. A. (1992). The effects of individualized music on elderly clients who are confused and agitated. Unpublished Master's thesis, University of Iowa, Iowa City.

Gerdner, L. A. (2012). Individualized music for dementia: Evolution and application of evidence-based protocol. World Journal of Psychiatry, 2(2), 26-32. doi:10.5498/wjp.v2.i2.26

Haute Autorité de Santé (February 2017). Isolement et contention en psychiatrie générale. Recommandation de bonne pratique. Retrieved from: https://www.hassante.fr/portail/jcms/c_2055362/fr/isolement-et-contention-en-psychiatrie-generale

Hoekstra, T., Lendemeijer, H. H. G., \& Jansen, M. G. M. (2004). Seclusion: the inside story. Journal of Psychiatric \& Mental Health Nursing, 11(3), 276-283. doi:10.1111/j.13652850.2003.00710.x

Holmes, D., Kennedy, S. L., \& Perron, A. (2004). The mentally ill and social exclusion: a critical examination of the use of seclusion from the patient's perspective. Issues in Mental Health Nursing, 25(6), 559-578. doi:10.1080/01612840490472101

Hsu, W.-C., \& Lai, H.-L. (2004). Effects of music on major depression in psychiatric inpatients. Archives of Psychiatric Nursing, 18(5), 193-199. doi:10.1016/j.apnu.2004.07.007

Jaafarpour, M., \& Khani, A. (2012). Evaluation of the nurses' job satisfaction, and its association with their moral sensitivities and well-being. Journal of Clinical and Diagnostic Research, 6(10), 1761-1764. doi:10.7860/JCDR/2012/4068.2638

Korkeila, H., Koivisto, A.-M., Paavilainen, E., \& Kylmä, J. (2016). Psychiatric Nurses’ Emotional and Ethical Experiences Regarding Seclusion and Restraint. Issues in Mental Health Nursing, 37(7), 464-475. doi:10.3109/01612840.2016.1163626

Lapointe, L., \& Rivard, S. (2005). Clinical information systems: Understanding and preventing their premature demise. Healthcare Quarterly, 8(2), 92-100. 
Larose, F., Grenon, V., \& Lafrance, S. (2002). Pratiques et profils d'utilisation des TICE chez les enseignants d'une université. In R. Guir (dir.), Pratiquer les TICE. Former les enseignants et les formateurs à de nouveaux usages (pp. 23-47). Bruxelles : De Boeck.

Larose, F., Grenon, V., \& Palm, S. (2004). Enquête sur l'état des pratiques d'appropriation et de mise en œuvre des ressources informatiques par les enseignantes et enseignants du Québec. Sherbrooke, Canada : Université de Sherbrooke, Centre de recherche sur l’intervention éducative.

Lin, S.-T., Yang, P., Lai, C.-Y., Su, Y.-Y., Yeh, Y.-C., Huang, M.-F., \& Chen, C.-C. (2011). Mental health implications of music: Insight from neuroscientific and clinical studies. Harvard Review of Psychiatry, 19(1), 34-46. doi:10.3109/10673229.2011.549769

Lund, H. N., Bertelsen, L. R., \& Bonde, L. O. (2016). Sound and music interventions in psychiatry at Aalborg University Hospital. Sound Effects, 6(1), 49-68.

Martinez, R. J., Grimm, M., \& Adamson, M. (1999). From the other side of the door: Patients views of seclusion. Journal of Psychosocial Nursing \& Mental Health Services, 37(3), 1322.

Mason, O. J., \& Brady, F. (2009). The psychotomimetic effects of short-term sensory deprivation. The Journal of Nervous and Mental Disease, 197, 783-785. doi:10.1097/NMD.0b013e3181b9760b

Meehan, T., Bergen, H., \& Fjeldsoe, K. (2004). Staff and patient perceptions of seclusion: has anything changed? Journal of Advanced Nursing, 47(1), 33-38. doi:10.1111/j.13652648.2004.03062.x

Mohr, W. K. (2010). Restraints and the code of ethics: An uneasy fit. Archives of Psychiatric Nursing, 24(1), 3-14. doi:10.1016/j.apnu.2009.03.003 
Morgan, K. A., Harris, A. W., Luscombe, G., Tran, Y., Herkes, G., \& Bartrop, R. W. (2010). The effect of music on brain wave functioning during an acute psychotic episode: A pilot study. Psychiatry Research, 178(2), 446- 448. doi:10.1016/j.psychres.2010.04.020

Moyle, W. (2003). Nurse-patient relationship: A dichotomy of expectations. International Journal of Mental Health Nursing, 12, 103-109. doi:10.1046/j.1440-0979.2003.00276.x

Needham, I., Abderhalden, C., Dassen, T., Haug, H. J., Fischer, J. E. (2000). Coercive procedures and facilities in Swiss psychiatry. Swiss Medical Weekly, 132, 253-258. doi:2002/19/smw-09926

Nelstrop, L., Chandler-Oatts, J., \& Bingley, W. (2006). A systematic review of the safety and effectiveness of restraint and seclusion as interventions for the short-term management of violence in adult psychiatric inpatient settings and emergency departments. Worldviews on evidence-based nursing, 3, 8-18. doi:10.1111/j.1741-6787.2006.00041.x

Rask, M., \& Brunt, D. (2007). Verbal and social interactions in the nurse-patient relationship in forensic psychiatric nursing care: A model and its philosophical and theoretical foundation. Nursing Inquiry, 14(2), 169-176. doi:10.1111/j.1440-1800.2007.00364.x

Sobol, M. G., Alverson, M., \& Lei, D. (1999). Nurses’ adoption of technology: Application of Rogers’ innovation diffusion model. Applied Nursing Research, 17(4), 231-238.

Steinert, T., \& Gebhardt, R. P. (2000). Erfolgen Zwangsmassnahmen willkürlich? Psychiatrische Praxis, 27, 282-285.

Stevenson, C., Barker, P., \& Fletcher, E. (2002). Judgement days: Developing an evaluation for an innovative nursing model. Journal of Psychiatric and Mental Health Nursing, 9, 271-276. doi:10.1046/j.1365-2850.2002.00472.x

Swiss Academy of Medical Sciences (2015). Coercive measures in medicine (English translation published in 2017). Retrieved from: 
https://www.samw.ch/en/Ethics/Vulnerable-patient-groups/Coercive-measures-inmedicine.html

Topo, P., Maki, O., Saarikalle, K., Clarke, N., Begley, E., Cahill, S., \& Gilliard, J. (2004). Assessment of a music based multimedia program for people with dementia. Dementia: The International Journal of Social Research and Practice, 3(3), 331-350.

Tricot, A., Plégat-Soutjos, F., Camps, J. F., Amiel, A., Lutz, G., \& Morcillo, A. (2003). Utilité, utilisabilité, acceptabilité : interpréter les relations entre trois dimensions de l'évaluation des EIAH. In N. Guin, B. De Lièvre, M. Trestini, \& B. Coulibaly (Eds.), Actes du congrès environnements informatiques pour l'apprentissage humain, Strasbourg (pp. 391-402).

United Nations (1948). Universal declaration of human rights. Retrieved from: http://www.un.org/en/universal-declaration-human-rights/

Venkatesch, V., \& Davis, F. D. (2000). A theoretical extension of the Technology Acceptance Model: Four longitudinal field studies. Management Science, 46(2), 186-204. doi:10.1287/mnsc.46.2.186.11926

Vignat, J.-P. (2009). De l’isolement au soin intensif. Santé Mentale, 139, 18-21.

Winnicott, D. W. (1975). Jeu et réalité. L’espace potentiel. Paris: Gallimard.

Wynn, R. (2004). Psychiatric inpatients' experiences with restraint. Journal of Forensic Psychiatry and Psychology, 15(1), 124-144._doi:10.1080/14789940410001655187

Zentner, M., Grandjean, D., \& Scherer, K. (2008). Emotions evoked by the sound of music: Characterization, classification, and measurement. Emotion, 8(4), 494-521. doi:10.1037/1528-3542.8.4.494.

Zung, W. W. (1965). A self-rating depression scale. Archives of General Psychiatry, 12, 6370. doi:10.1001/archpsyc.1965.01720310065008 


\section{Appendix. Music selection}

\begin{tabular}{|l|l|}
\hline \multicolumn{2}{|l|}{ Category 1. Joyful activation } \\
\hline $\begin{array}{l}\text { Italian concerto for piano solo } \\
\text { Johann Sebastian Bach (1685-1750) }\end{array}$ & $\begin{array}{l}3^{\text {rd }} \text { movement, presto } \\
\text { Alfred Brendel (piano) }\end{array}$ \\
\hline Polka à Micheneau & $\begin{array}{l}\text { Traditional polka collected in the Poitou } \\
\text { Ciac Boum }\end{array}$ \\
Album Ciac Boum Vol. 3 (2012) & $\begin{array}{l}\text { Samba by Jayme Silva and Neuza Teixeira } \\
\text { Stan Getz (saxophone) and Charlie Byrd (guitar) }\end{array}$ \\
\hline O Pato (the duck) & $\begin{array}{l}\text { Michala Petri (recorder) and Klaus Thunemann } \\
\text { (bassoon) }\end{array}$ \\
\hline $\begin{array}{l}\text { Concerto for recorder and bassoon } \\
\text { Georg Philipp Telemann (1681-1767) }\end{array}$ & Rabbinical School Dropouts \\
\hline Warp to Level Three & \\
Cosmic Tree album (2002) & \\
\hline
\end{tabular}

\section{Category 2. Nostalgia}

Kol Nidrei for violoncello and orchestra

Max Bruch (1838-1920)

Rylynn

Art of Motion album (2005)

Quartet for piano, violin, alto, violoncello Robert Schumann (1810-1856)

Stèle in memoriam Igor Stravinsky

Alexander Tansmann (1897-1986)

Milonga Del Angel

Astor Piazzola (1921-1992)

Adagio on Hebrew Melodies

Martin Ostertag (violoncello)

Andy Mc Kee (guitar)

$3^{\text {rd }}$ movement

Elégie

Slovak State Philharmonic Orchestra

Violentango

Buenos Aires 3.a.m. album (2007)

\section{Category 3. Tension}

\section{Anvil of Crom}

Soundtrack of Conan Le Barbare (1982)

La mer, 3 esquisses symphoniques

Claude Debussy (1862-1918)

Concerto for orchestra

Witold Lutoslawski (1913-1994)

Prince of Darkness

Soundtrack of Prince of Darkness (1987)

Souvenirs

Unue album (2009)
Basil Poledouris (composition) and Greg McRitchie (orchestration)

No 3, Dialogue du vent et de la mer

Los Angeles Philharmonic Orchestra

Intrada, allegro maestoso

Basel Sinfonietta

Alan Howarth and John Carpenter

Yom (clarinet) and Denis Cuniot (piano)

\section{Category 4. Calm}

\begin{tabular}{|l|l|}
\hline $\begin{array}{l}\text { Astrakan Café } \\
\text { Astrakan Café album (2000) }\end{array}$ & Anouar Brahem (oud) \\
\hline $\begin{array}{l}\text { Consolation in d flat } \\
\text { Franz Liszt (1811-1886) }\end{array}$ & Sylvia Cápová (piano) \\
\hline $\begin{array}{l}\text { It Might as Well Be Spring } \\
\text { Songs We Know album (2000) }\end{array}$ & Bill Frisell (guitar) and Fred Hersch (piano) \\
\hline $\begin{array}{l}\text { Maquey Blues } \\
\text { Maquey Blues album (2011) }\end{array}$ & L’ironie du son \\
\hline $\begin{array}{l}\text { Peer Gynt Suite } \\
\text { Edvard Grieg (1843-1907) }\end{array}$ & Morning Mood \\
\hline
\end{tabular}




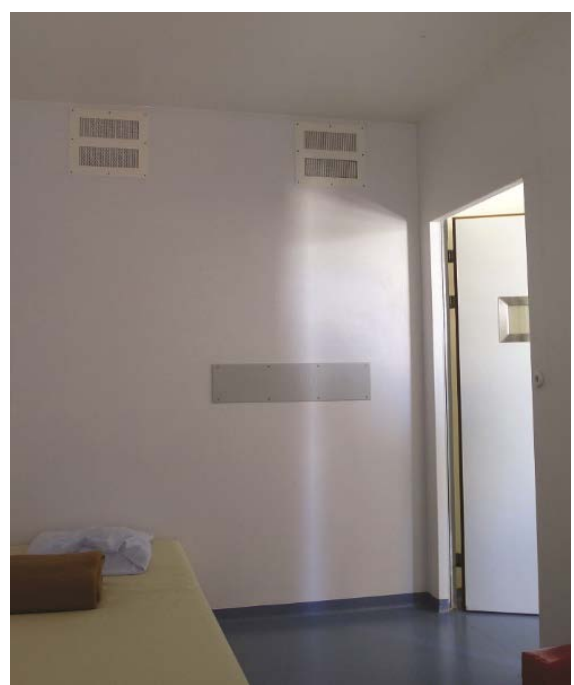

1a. Tactile interface

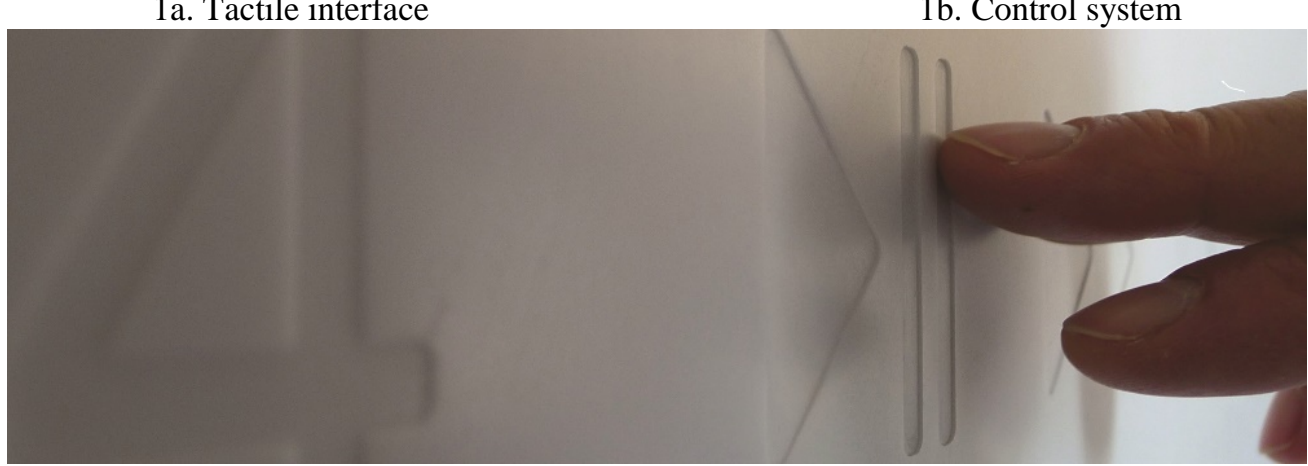

1c. Buttons

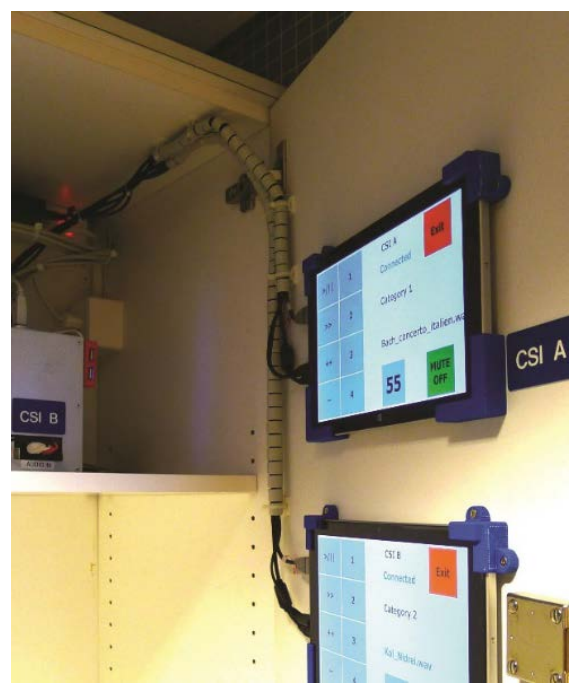

1b. Control system

Fig 1. The music listening device 